\title{
Observations and Parameterizations of Surfzone Albedo
}

\author{
Gregory SinnetT*AND FALK FEDdERSEN \\ Scripps Insitution of Oceanography \\ University of California San Diego \\ La Jolla CA 92093
}

May 25, 2016

Under consideration for publication in Methods in Oceanography

*Corresponding Author Address: 9500 Gilman Drive, La Jolla CA 92093-0209, gsinnett@ ucsd.edu 


\begin{abstract}
Incident shortwave solar radiation entering the ocean depends on albedo $\alpha$ and plays an important role in the temperature variability and pathogen mortality of the nearshore region. As foam has an elevated albedo, open-ocean albedo parameterizations include whitecapping effects through a wind-based foam fraction. However, surfzone depth-limited wave breaking does not require wind. Surfzone albedo observations are very rare, the variability of surfzone albedo is not known, and parameterizations are not available. New, year-long upwelling and downwelling shortwave radiation observations were made from the Scripps Institution of Oceanography pier spanning the surfzone and inner-shelf. Surfzone albedo was elevated due to foam with mean observed albedo of $\alpha=0.15$ and one-minute average albedo as high as $\alpha=0.45$, far exceeding expected albedo (0.06) from standard parameterizations. Using a pier-mounted GoPro camera, an image-based albedo parameterization is developed that estimates the fractional foam area to derive albedo. This parameterization has high skill $\left(r^{2}=0.90\right)$ on time scales as short as a wave period $(9 \mathrm{~s})$. A second wave-model based parameterization for (hourly) averaged albedo is developed relating the non-dimensional roller energy dissipation to the mean foam fraction and thus albedo. The parameterization has good skill $\left(r^{2}=0.68\right)$ and resolves cross-shore albedo variations. These new parameterizations can be used where imagery is available or wave models are applicable, and can be used to constrain local heat budgets and pathogen mortality.
\end{abstract}




\section{Introduction}

2 The nearshore region ( $\leq 7 \mathrm{~m}$ water depth) is critical both economically and ecologically. The region is a center for tourism, recreation, and commercial use, and is also home to a wide variety of fish, birds, plants and invertebrates. Water temperature is an important ecological aspect, affecting growth rates, recruitment rates, egg-mass production, pathogen ecology and many other factors (e.g., Phillips, 2005; Fischer and Thatje, 2008; Broitman et al., 2005; Goodwin et al., 2012; Halliday, 2012). In this sensitive region, incident shortwave solar radiation entering the ocean $\left(Q_{\mathrm{sw}}\right)$ plays an important role in both the temperature variability (Sinnett and Feddersen, 2014) and pathogen mortality through UV-B photobiological damage (e.g., Sinton et al., 1994, 2002).

Shortwave solar radiation entering the ocean is defined as

$$
Q_{\mathrm{sw}}=Q_{\mathrm{d}}-Q_{\mathrm{u}}
$$

where $Q_{\mathrm{d}}$ is the total downwelling (downward) component of solar shortwave radiation, and $Q_{\mathrm{u}}$ is the upwelling (upward) component of shortwave radiation reflected from the ocean surface. The albedo $\alpha$ (surface reflection coefficient) is defined as

$$
\alpha=\frac{Q_{\mathrm{u}}}{Q_{\mathrm{d}}}
$$

making

$$
Q_{\mathrm{sw}}=(1-\alpha) Q_{\mathrm{d}}
$$

Under direct sun, open ocean albedo $\alpha$ depends on the solar zenith angle $\theta_{\mathrm{s}}$ (the angle of sun declination from vertical) and has a daily average of $\alpha \approx 0.06$ (Payne, 1972; Briegleb et al., 1986; Taylor et al., 1996). Under cloudy (diffusely lit) skies, open ocean albedo is near 0.06 and is independent of $\theta_{\mathrm{s}}$ (Payne, 1972). However, wind generates ocean whitecaps (foam) (e.g., Monahan, 1971; Monahan and Muircheartaigh, 1980) associated with elevated albedo. Wind also enhances 
the sea-surface slope variability (e.g., Ross and Dion, 2007), which affects albedo at large solar zenith angles (e.g., Saunders, 1967). Laboratory measurements indicate that pure foam has albedo $\alpha=0.55$ (Whitlock et al., 1982). For a fractional surface coverage of foam $\zeta$, the combined effects of foam and open water on albedo are often (e.g., Koepke, 1984; Frouin et al., 1996; Jin et al., 2011) represented as

$$
\alpha=\zeta \alpha_{\mathrm{f}}+(1-\zeta) \alpha_{\theta}
$$

where $\alpha_{\mathrm{f}}$ is the foam albedo, and $\alpha_{\theta}$ is the parameterized solar zenith angle dependent open ocean albedo (e.g., Taylor et al., 1996). The foam fraction $\zeta$ from open ocean whitecapping has been parameterized using a surface wind speed $\left|u_{\mathrm{w}}\right|$ dependence (e.g., Hansen et al., 1983; Jin et al., 2004, 2011), but has a negligible effect on albedo (less than 0.002) for winds $\left|u_{\mathrm{w}}\right|<12 \mathrm{~m} \mathrm{~s}^{-1}$ (Payne, 1972; Moore et al., 2000; Frouin et al., 2001).

In the surfzone, foam is generated by depth-limited wave breaking regardless of wind, potentially elevating surfzone $\alpha$ and reducing $Q_{\text {sw }}$. Nearshore temperature evolution (e.g., Sinnett and Feddersen, 2014; Hally-Rosendahl et al., 2014) depends strongly on $Q_{\mathrm{sw}}$ in the surfzone and inner-shelf, the region just seaward of the surfzone. Elevated surfzone albedo may also help explain reduced surfzone pathogen mortality relative to the inner-shelf (e.g., Rippy et al., 2013a,b) making the surfzone albedo an important factor controlling the ecology of the region. Limited (21 min) surfzone albedo observations at 440-650 $\mathrm{nm}$ wavelengths reported elevated albedo up to 0.4-0.6, compared to 0.06 observed in the inner-shelf (Frouin et al., 1996), potentially influencing the surfzone heat budget (Sinnett and Feddersen, 2014). However, no other surfzone albedo observations have been published (to our knowledge) and depth-limited wave-breaking albedo parameterizations do not exist. Thus, the magnitude and variability of surfzone albedo is not known, nor are its impacts on nearshore temperature and pathogen mortality. Making surfzone albedo observations is difficult, thus surfzone albedo parameterizations are needed.

Results from a year-long experiment at the Scripps Institution of Oceanography (SIO) pier 
measuring nearshore albedo under a wide variety of conditions are presented here, together with tests of two surfzone albedo parameterizations. As surfzone foam is visible in both time-elapsed (e.g., Lippmann and Holman, 1990; Holland et al., 1997; Almar et al., 2010) and snapshot (e.g., Stockdon and Holman, 2000; Chickadel et al., 2003) optical images, the first parameterization uses optical images to estimate foam fraction and albedo. The second parameterization uses a wave and roller transformation model to estimate foam fraction and albedo. The experiment methods and observations are described in section 2. Results and the two parameterizations are presented in section 3, discussed in section 4, and summarized in section 5.

\section{Methods and Observations}

\subsection{Experiment Description}

Shortwave solar radiation, wave statistics, winds, and water depth were measured between October 25th, 2014 and October 25th, 2015 at the SIO pier (Figure 1a), La Jolla, California (lat 32.867, lon -117.257). Cross-shore $(x)$ bathymetry profiles were made at 0.5 to 1 month intervals (see dots in Figure 3a) between $x=0 \mathrm{~m}$ (the cross-shore location of the shoreline extent at mean tide at the start of the experiment) and the pier end at $x=-270 \mathrm{~m}$. NOAA tide gauge station 9410230 at the SIO pier end (in $\approx 7 \mathrm{~m}$ water depth) measured the water level at 6 minute intervals. A representative cross-sectional view (Figure 1b) shows the mean bathymetric profile, the Mean Tide Level $($ MTL) reference height $(h=0)$, and tidal standard deviation $(\approx 0.5 \mathrm{~m})$.

Downwelling, $Q_{\mathrm{d}}$ and upwelling, $Q_{\mathrm{u}}$ shortwave solar radiation was measured by a Campbell Scientific NR01 research grade four-way radiometer (Figure 2b) having two shortwave radiation sensors (wavelengths from $305 \mathrm{~nm}$ to $2,800 \mathrm{~nm}$ ) with $2.9 \mathrm{~s}$ response time and cosine angle spatial response over a $180^{\circ}$ field of view. The sensor noise level is $<1.5 \%$ of the signal, instrument drift is expected to be $<1 \%$ per year, and instrument tilt errors are expected to be $<2 \%$. Both 

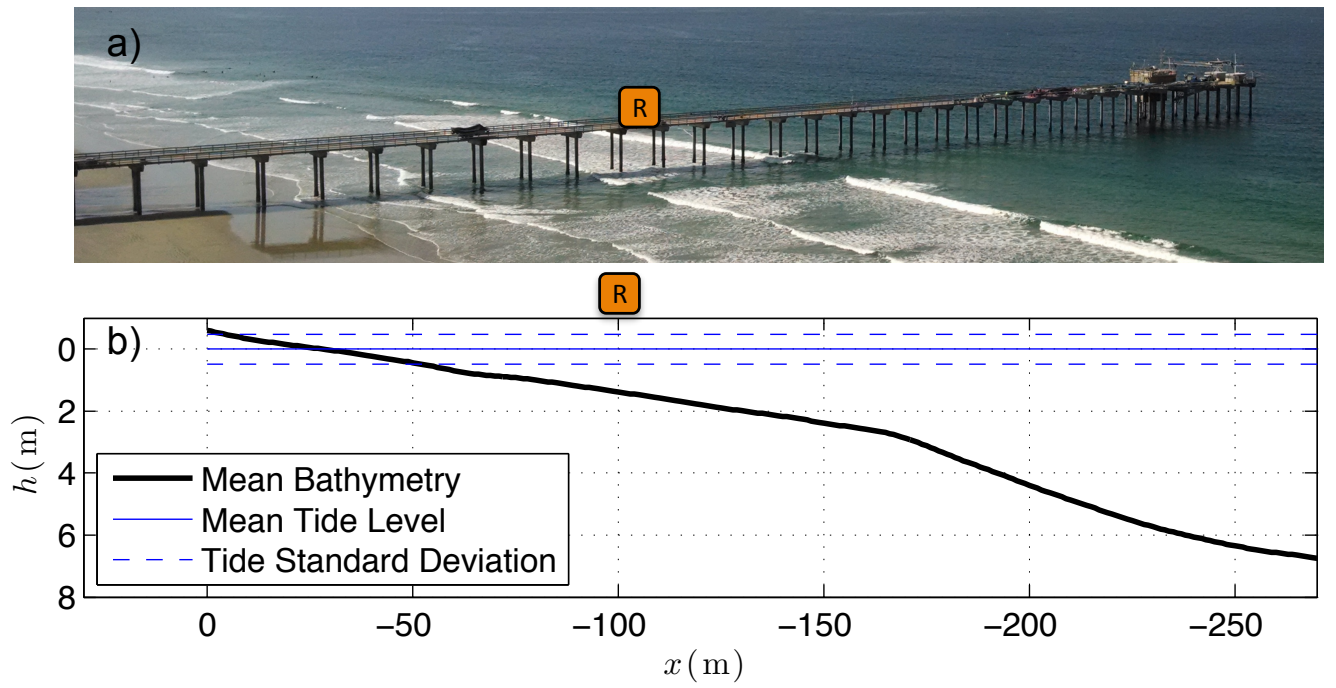

Figure 1: (a) Photo of the Scripps Institution of Oceanography (SIO) pier (La Jolla, California) and nearshore region at low tide. (b) Mean cross-shore bathymetric profile with mean tide level and approximate tidal extents. The radiometer is located at $x_{\mathrm{R}}=-100 \mathrm{~m}$ (indicated with an orange marker), a location frequently within the surfzone.

radiometer sensors were calibrated within one year of their deployment according to ISO 9847.

The NR01 radiometer was attached to the end of a custom designed boom arm (Figure $2 b$ ) and fitted to the south side of the SIO pier at $x_{\mathrm{R}}=-100 \mathrm{~m}$. The cross-shore deployment location was chosen so that the radiometer would observe the surfzone roughly two-thirds of the time depending on the tidal depth and wave height. The radiometer was mounted $6.5 \mathrm{~m}$ above MTL to avoid significant spray from breaking waves, while assuring that more than $90 \%$ of the upwelling signal was confined to a $14 \mathrm{~m}$ radius watch circle beneath the instrument. The mounting boom was hinged at the pier end and mid-boom arm (Figure 2c arrows) allowing it to swing parallel and pivot up to the pier deck for cleaning at roughly 5 day intervals.

Generally, the radiometer sampled $Q_{\mathrm{d}}$ and $Q_{\mathrm{u}}$ continuously at $1 \mathrm{~Hz}$, storing the 1 min mean and standard deviation. On 9 days, a GoPro camera with a $72^{\circ}$ vertical and $94^{\circ}$ horizontal field of view was mounted on the pier deck approximately $2.5 \mathrm{~m}$ above the radiometer looking down at the water at $\approx 45^{\circ}$ from horizontal. The camera captured images of the surfzone conditions at two second intervals with a 1/4000 second shutter speed, f/2.8 aperture value and ISO 100 speed 


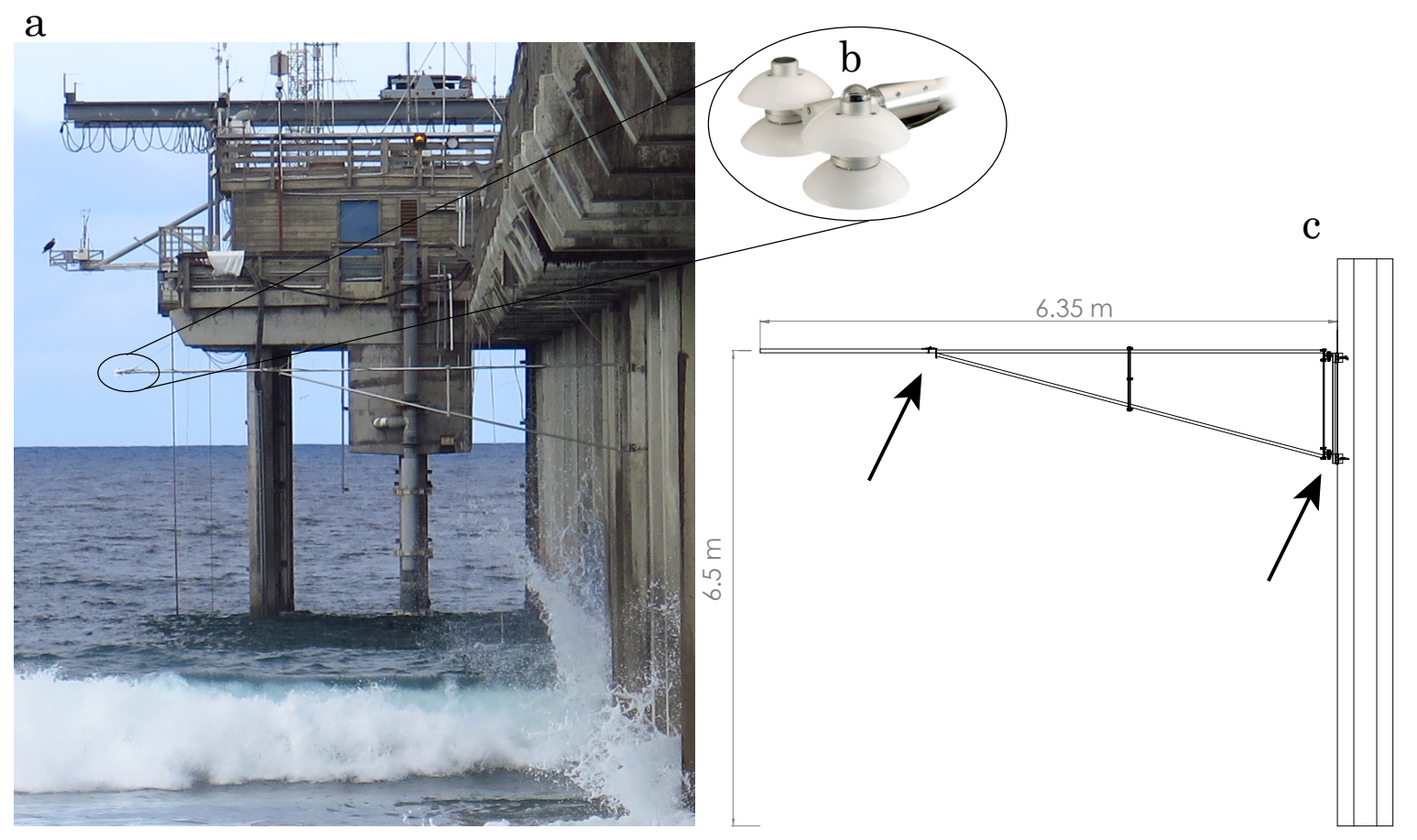

Figure 2: (a) Photo of the Campbell Scientific NR01 radiometer deployed over the surfzone, mounted on the south side of the SIO pier. (b) A close-up of the NR01 radiometer, consisting of upwelling and downwelling shortwave radiation sensors. (c) A schematic of the boom mount allowing radiometer deployment $6.5 \mathrm{~m}$ above MTL at a distance $6.35 \mathrm{~m}$ from the pier pilings. Hinges (arrows) allow the boom to pivot laterally and swing vertically for regular radiometer cleaning.

rating. During this time the radiometer stored $1 \mathrm{~Hz}$ samples directly, allowing image and albedo comparison.

At pier-end, hourly significant wave height $H_{\mathrm{s}}^{(p)}$ and peak period $T_{\mathrm{p}}$ were estimated by the Coastal Data Information Program wave gauge. During times when the wave gauge was offline (July 29 to August 20, 2015) a realtime spectral refraction wave model initialized from offshore buoys (O'Reilly and Guza, 1991; O'Reilly and Guza, 1998) with very high skill was used. Winds were observed by the NOAA station at the pier end $18 \mathrm{~m}$ above MTL and reported as six-minute averaged values. The experiment site latitude and local time was used to calculate solar zenith angle $\theta_{\mathrm{s}}$ based on Reda and Andreas (2008). 

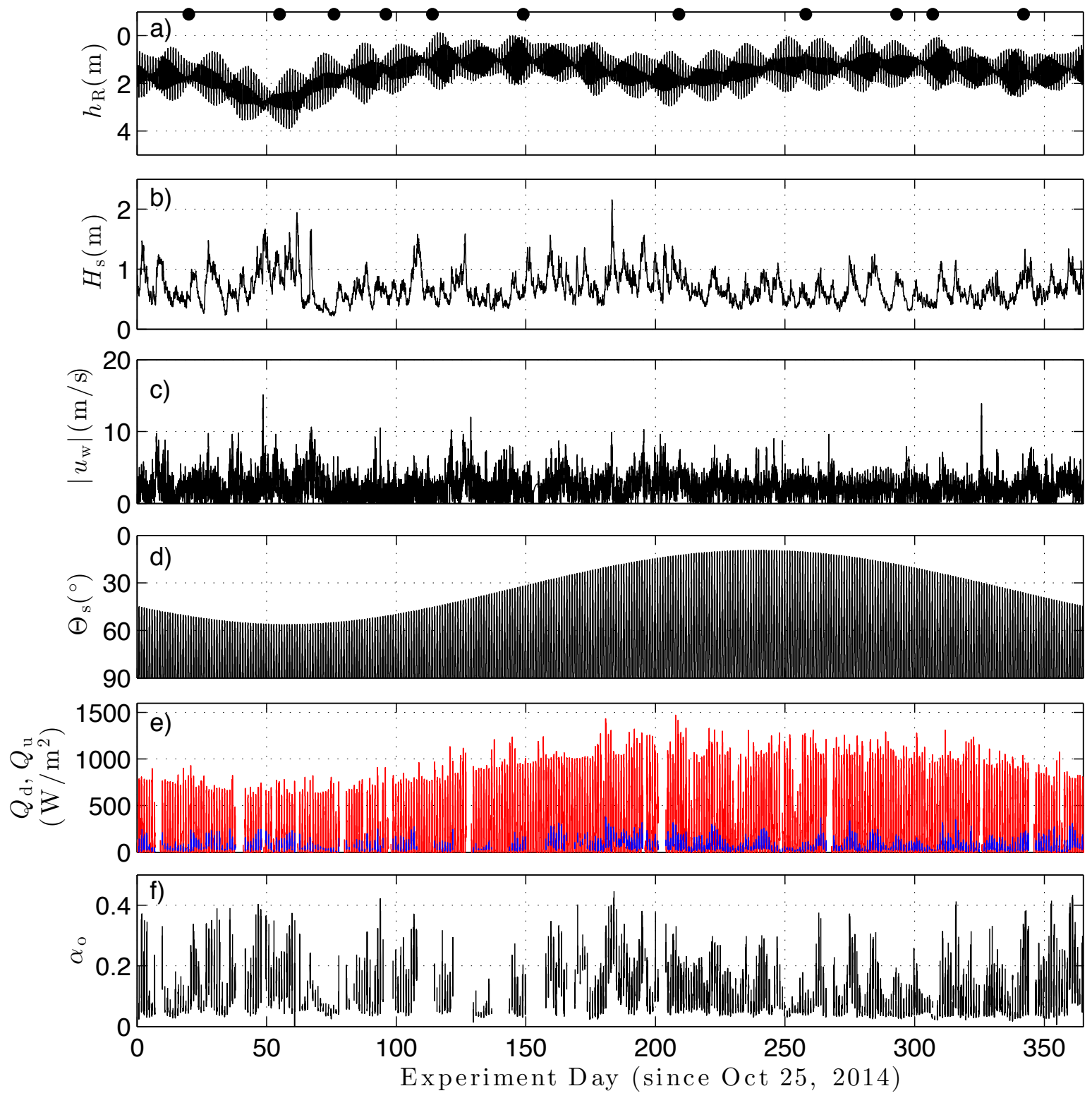

Figure 3: Hourly time-series over the year-long experimental period of (a) water depth $h_{\mathrm{R}}$ at the radiometer cross-shore location $\left(x_{\mathrm{R}}=-100 \mathrm{~m}\right)$, (b) pier-end significant wave height $H_{\mathrm{s}}$, (c) wind speed $\left|u_{\mathrm{w}}\right|$, (d) solar zenith angle $\theta_{\mathrm{s}}$, (e) observed downwelling $Q_{\mathrm{d}}$ (red) and upwelling $Q_{\mathrm{u}}$ (blue) short-wave solar radiation, and (f) observed albedo $\alpha_{\mathrm{o}}=Q_{\mathrm{u}} / Q_{\mathrm{d}}$. Times when $Q_{\mathrm{d}}$ or $Q_{\mathrm{u}}$ were corrupted are removed in (e) and (f). 


\subsection{Observations}

At $x_{\mathrm{R}}$, the water depth $h_{\mathrm{R}}$ varied due to tidal changes in sea surface elevation and on longer time scales due to bathymetry changes (Figure 3a). Beach profile evolution followed a wintertime (defined here as day 26 on November 20, 2014 to day 126 on February 28, 2015) erosion and summertime (day 212 on May 25, 2015 to day 312 on September 2, 2015) accretion pattern, characteristic of southern California beaches (e.g., Ludka et al., 2015).

Pier-end significant wave height $H_{\mathrm{s}}^{(p)}$ varied between $0.22 \mathrm{~m}$ and $2.16 \mathrm{~m}$ and peak period $T_{\mathrm{p}}$ between $3 \mathrm{~s}$ and $18 \mathrm{~s}$ (not shown) with increased wave activity occurring every few days, modulated seasonally with typically stronger wintertime and weaker summertime wave events (Figure 3b). Winds were typically calm, with average wind speed $\left|u_{\mathrm{w}}\right|$ of $2.25 \mathrm{~m} \mathrm{~s}^{-1}$ having diurnal variability and occasional peaks above $10 \mathrm{~m} \mathrm{~s}^{-1}$, particularly in winter (Figure 3c). Solar zenith angle fluctuated diurnally with daily minimum $\theta_{\mathrm{s}}$ varying on an annual time-scale between between $56.31^{\circ}$ and $9.43^{\circ}$ near the winter and summer solstice respectively (Figure 3d).

Foam-free albedo depends on $\theta_{\mathrm{s}}$ in direct light (clear sky) but not in diffuse light (cloudy skies) (Payne, 1972). Lighting conditions are characterized with the atmospheric transmittance $T_{\mathrm{r}}$ defined as the ratio of the observed downwelling radiation $Q_{\mathrm{d}}$ to the theoretical maximum $Q_{\mathrm{d}}$,

$$
T_{\mathrm{r}}=\frac{Q_{\mathrm{d}}}{S \cos \left(\theta_{\mathrm{s}}\right) \gamma^{-2}}
$$

where $S$ is the solar constant and $\gamma$ is the ratio of the actual to mean earth-sun separation distance. Direct light conditions are defined when $T_{\mathrm{r}}>0.6$, and diffuse light conditions are defined when $T_{\mathrm{r}}<0.3$. The observations were made in $58 \%$ clear sky, $16 \%$ cloudy sky and $26 \%$ mixed sky $\left(0.3<T_{\mathrm{r}}<0.6\right)$ conditions.

Both $Q_{\mathrm{d}}$ and $Q_{\mathrm{u}}$ observations were removed during rain or heavy fog events when the radiometer was affected by moisture. In addition, $Q_{\mathrm{d}}$ and $Q_{\mathrm{u}}$ observations were removed when $\theta_{\mathrm{s}}>60^{\circ}$ to avoid nighttime and times when the sun was behind a coastal bluff or very near the horizon. 
The radiometer was too close to the cross-shore location of exposed sand when, at $x_{\mathrm{R}}$, the depth $h_{\mathrm{R}}<1.3 \mathrm{~m}$ (approximately $38 \%$ of the time). These observations were also removed. The boom arm extended $6.35 \mathrm{~m}$ to the south of the pier to avoid pier shadow under clear skies, when the vast majority of light arrives from the southern sky. However, when the solar azimuth angle $\phi<109^{\circ}$ $(<0.1 \%$ of the time), pier shadows were cast under the radiometer and these observations were removed. In total, $\approx 50 \%$ of daytime data was retained. For pure diffuse light conditions, the true $Q_{\mathrm{u}}$ is slightly underestimated primarily due to pier deck shadow reducing the available downwelling light and also due to pier pilings directly blocking a fraction of the upwelling light from the north. This effect is corrected following Payne (1972) so that the upwelling shortwave radiation is

$$
Q_{\mathrm{u}}=Q_{\mathrm{mu}}\left[1+0.15\left(1-T_{\mathrm{r}}\right)\right],
$$

where $Q_{\mathrm{mu}}$ is the measured upwelling shortwave radiation, $T_{\mathrm{r}}$ is the atmospheric transmittance, and pier geometry sets the coefficient $(0.15)$. This correction has no effect on the results.

Downwelling shortwave radiation $Q_{\mathrm{d}}$ had a predominantly diurnal pattern with seasonal longterm variability and short $(<6 \mathrm{~h})$ time-scale variability due to clouds (red in Figure 3e). Clear-sky daily maximum $Q_{\mathrm{d}}$ varied between $610 \mathrm{~W} \mathrm{~m}^{-2}$ in wintertime to $1064 \mathrm{~W} \mathrm{~m}^{-2}$ in the summer. Clouds typically reduced $Q_{\mathrm{d}}$, but also increased $Q_{\mathrm{d}}$ for short periods (seconds to minutes) due to magnification caused by the "edge-of-cloud" effect (e.g., Davies, 1978; Coakley and Davies, 1986). Reflected shortwave upwelling radiation $Q_{\mathrm{u}}$ (blue in Figure 3e) also varied on diurnal time scales, but contained variability on shorter time scales as well. A time series of over 70,000 oneminute averaged observed albedo observations $\alpha_{\mathrm{o}}$ was generated from the the retained $Q_{\mathrm{d}}$ and $Q_{\mathrm{u}}$ with (2). Observed albedo $\alpha_{\mathrm{o}}$ varied from 0.04 to 0.45 on a range of timescales from minutes to many days (Figure 3f). 

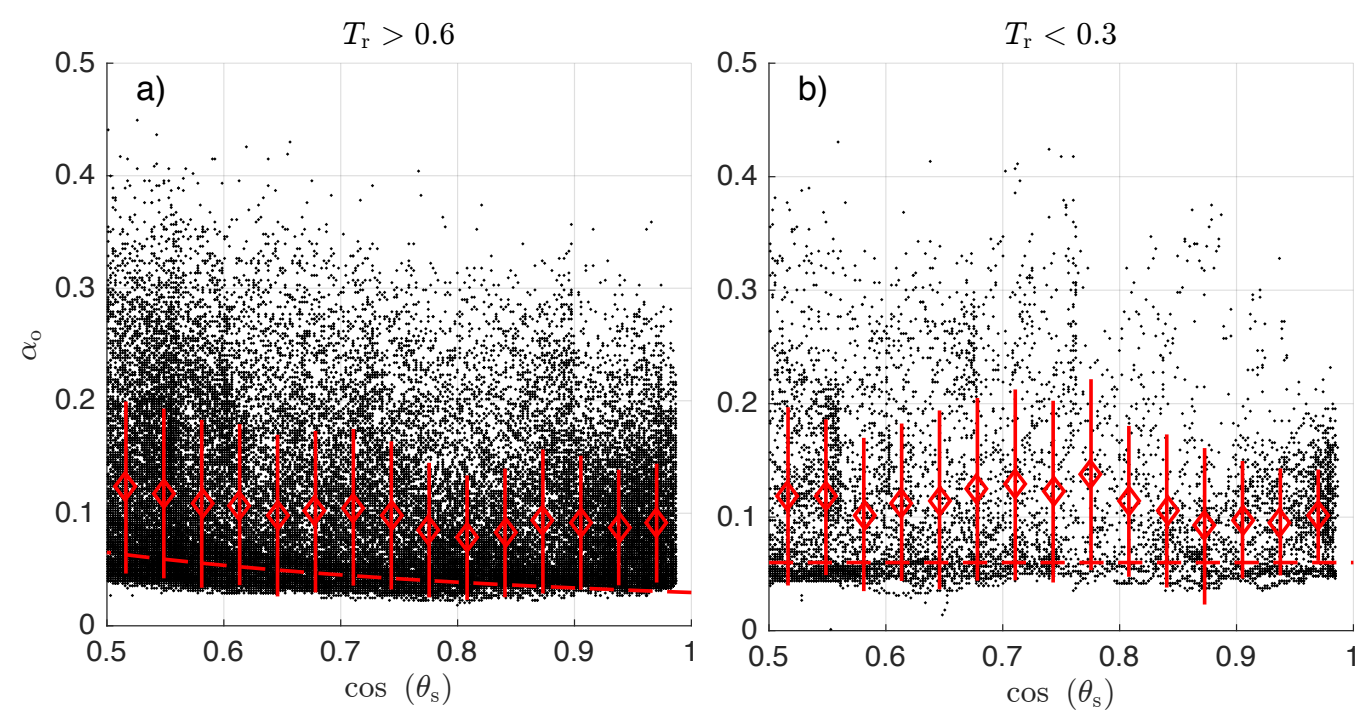

Figure 4: One-minute averaged observed albedo $\alpha_{\mathrm{o}}$ versus $\cos \left(\theta_{\mathrm{s}}\right)$ under (a) clear sky conditions $\left(T_{\mathrm{r}}>0.6\right)$ and (b) diffuse light conditions $\left(T_{\mathrm{r}}<0.3\right)$. Binned means (red diamonds) and \pm one standard deviation (red vertical lines) of $\alpha_{\mathrm{o}}$ are mostly elevated over the $\theta_{\mathrm{s}}$-only based Taylor et al. (1996) parameterization $\alpha_{\theta_{\mathrm{s}}}$ (red dashed).

\section{Results}

\subsection{Albedo dependence on $\theta_{\mathrm{s}}$ and waves}

Here, the one-minute averaged observed albedo $\alpha_{\mathrm{o}}$ is directly compared to solar zenith angle $\left(\theta_{\mathrm{s}}\right)$ dependent parameterizations that assume no foam (e.g., Taylor et al., 1996). Observed one-minute averaged albedo $\alpha_{\mathrm{o}}$ are significantly elevated from a solar zenith angle dependent parameterization $\alpha_{\theta}$ (compare dots to red dashed in Figure 4) for both clear and diffuse light conditions. For $\cos \left|\theta_{\mathrm{s}}\right|>0.5, \alpha_{\mathrm{o}}$ varied from near 0.04, typical of $\alpha_{\theta}$, to 0.45 , far exceeding $\alpha_{\theta}$ (Figure 4). Over all conditions spanning both the surfzone and inner-shelf, the mean albedo was 0.11 , nearly twice previous estimates of open-ocean daily averaged albedo (e.g., Payne, 1972). Although the minimum $\alpha_{\mathrm{o}}$ values are consistent with $\alpha_{\theta}$ under both light conditions, the binned mean $\alpha_{\mathrm{o}}$ is roughly one $\alpha_{\mathrm{o}}$ standard deviation higher than $\alpha_{\theta}$ for all $\theta_{\mathrm{S}}$ in both clear and diffuse light conditions (compare red diamonds and vertical bars to red dashed curve, Figure 4). 
Depth-limited wave breaking is often well determined by the ratio of local wave height to water depth $H_{\mathrm{s}} / h$ (e.g., Thornton and Guza, 1983). To investigate whether the elevated $\alpha_{\mathrm{o}}$ is due to breaking-wave generated foam or rather due to surface wind speed (as in open ocean parameterizations), the relationship between $\left\langle\alpha_{\mathrm{o}}\right\rangle$ (where \langle\rangle denotes an hourly average) and $H_{\mathrm{s}}^{(p)} / h_{\mathrm{R}}$ is examined, where $H_{\mathrm{s}}^{(p)}$ is the pier-end $(x=-270 \mathrm{~m})$ significant wave height and $h_{\mathrm{R}}$ is the water depth at the radiometer $\left(x_{\mathrm{R}}=-100 \mathrm{~m}\right)$. Hourly-averaged $\left\langle\alpha_{\mathrm{o}}\right\rangle$ varies between $0.04-0.33$ and is strongly related to $H_{\mathrm{S}}^{(p)} / h_{\mathrm{R}}$ (Figure 5a) with $r^{2}=0.64$. Wind speeds at this location were typically weak; mean winds were $\approx 2 \mathrm{~m} \mathrm{~s}^{-1}$, and sustained winds over $4 \mathrm{~m} \mathrm{~s}^{-1}$ were observed less than $12 \%$ of the time. As expected, winds were not correlated with $\left\langle\alpha_{\mathrm{o}}\right\rangle$ (Figure 5b) since total ocean reflectance when winds are less than $8 \mathrm{~m} \mathrm{~s}^{-1}$ is negligible (Koepke, 1984) and whitecapping due to winds below $15 \mathrm{~m} \mathrm{~s}^{-1}$ has not been observed to enhance albedo (Payne, 1972; Frouin et al., 2001). The relationship between $\left\langle\alpha_{\mathrm{o}}\right\rangle$ and $H_{\mathrm{S}}^{(p)} / h_{\mathrm{R}}$ demonstrates that for larger incident waves $H_{\mathrm{s}}^{(p)}$ or smaller local water depth $h_{\mathrm{R}},\left\langle\alpha_{\mathrm{o}}\right\rangle$ is elevated in a consistent manner and confirms that the breaking-wave foam strongly contributes to the observed albedo, motivating the following two parameterization approaches.

\subsection{Image-Based Parameterization}

Following open-ocean whitecapping parameterizations (e.g., Hansen et al., 1983; Jin et al., 2004, 2011), surfzone albedo is expected to depend on $\theta_{\mathrm{s}}$ and the breaking-wave generated foam fraction $\zeta_{\mathrm{w}}$. Time-averaged and snapshot images of the surfzone have successfully been used to identify areas with elevated foam (e.g., Lippmann and Holman, 1990; Stockdon and Holman, 2000). Here, images from the pier-mounted GoPro camera are used to estimate $\zeta_{\mathrm{w}}$ and compared to 1-Hz sampled $\alpha_{\mathrm{o}}$ to derive an image-based albedo parameterization.

For a broken wave with extensive foam (Figure 6a), the 1-Hz sampled $\alpha_{\mathrm{o}}=0.33$, elevated above $\alpha_{\theta}=0.06$. In contrast, for foam-free conditions (Figure 6b), $\alpha_{\mathrm{o}}=0.05$, consistent with expected $\alpha_{\theta}$. The images were cropped and converted to 0-255 count grayscale $G$ (Figures $6 \mathrm{c}$ and 

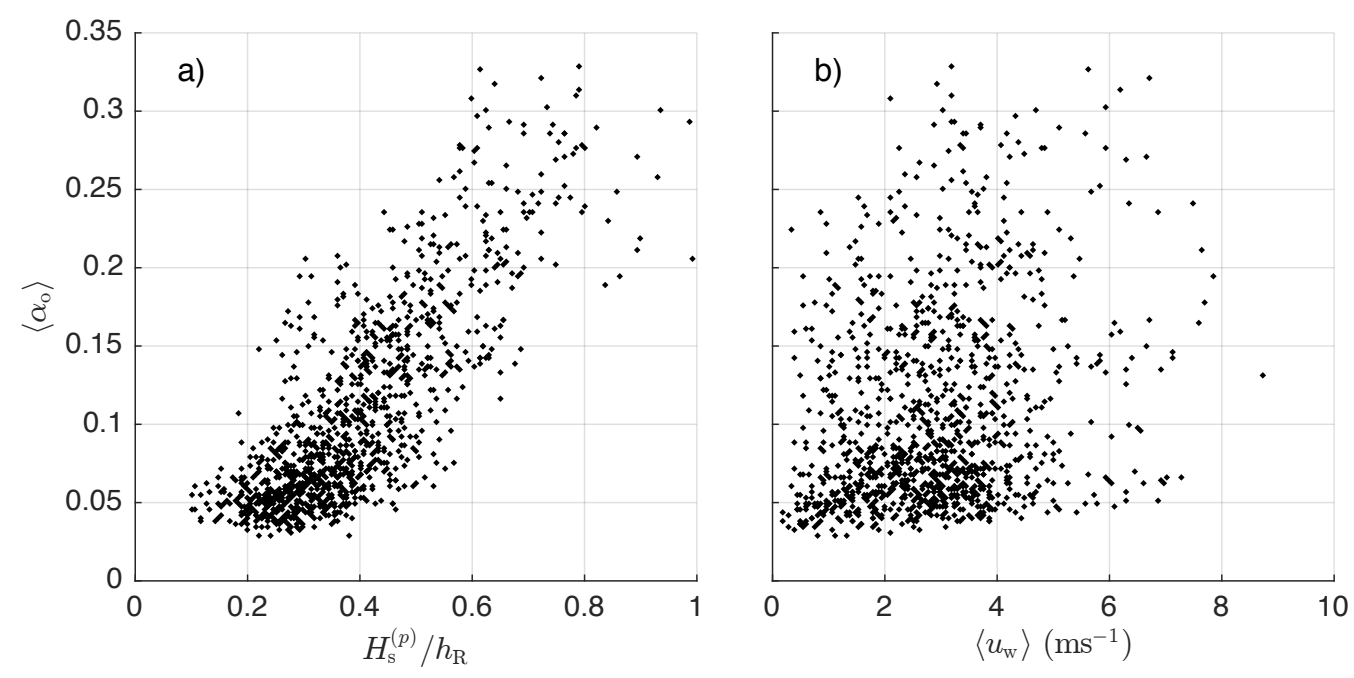

Figure 5: Hourly averaged observed albedo $\left\langle\alpha_{\mathrm{o}}\right\rangle$ versus a) hourly-observed $H_{\mathrm{s}}^{(p)} / h_{\mathrm{R}}$ where $H_{\mathrm{s}}^{(p)}$ is the significant wave height measured at the pier-end $(x=-270 \mathrm{~m})$ and $h_{\mathrm{R}}$ is the water depth at the radiometer, and b) hourly averaged wind speed. Correlation between albedo and wind speed at this site $\left(r^{2}=0.06\right)$ is not significant from zero at the $95 \%$ confidence interval, however albedo is correlated with $H_{\mathrm{s}}^{(p)} / h_{\mathrm{R}}\left(r^{2}=0.64\right)$.

d) representing the ocean surface light intensity. The grayscale value $G=0.2989 r+0.5870 g+$ $0.1140 b$, where $r, b$ and $g$ are the red, blue and green components respectively, retain luminance while removing hue and saturation. Elevated $G$ can result from foam (white areas in Figure 6c) or sun glint (specular reflection, upper left Figure 6d). Typically, sun glint is brighter than foam, which is brighter than foam-free areas, allowing for differentiation between regions using grayscale values.

For the breaking case, the probability density function (PDF) of grayscale pixel values $p(G)$ contains three peaks near 100, 190 and 255 (Figure 6e), corresponding to areas of open water, foam and sun glint in Figure 6a. For the non-breaking case, $p(G)$ only has two peaks near 100 and 255 (Figure 6d) corresponding to open water and sun glint. The peak near 190 associated with foam (Figure 6c) is not present. To quantify image area containing open water, foam and sun glint, all grayscale PDFs are first averaged together forming a mean $\bar{p}(G)$ (not shown). Similar to Carini et al. (2015), PDF curvature $\bar{p}^{\prime \prime}(G)$ maxima define cutoff values between open water, 
whitewater and sun glint (lines on Figure 6e,f), here found to be $G=170$ and $G=230$. As foam is not a specular reflector (Monahan et al., 1986), sun glint must be from foam free regions and is thus classified as open water. The pixel fraction (as a proxy for surface area) of foam $\zeta_{\mathrm{w}}$ is then calculated. For the breaking case (Figure 6e), the pixel fraction attributed to foam was $\zeta_{\mathrm{w}}=0.55$, and for the non-breaking case (Figure 6f) $\zeta_{\mathrm{w}}=0.03$. This approach is applied to all images, creating a time series of foam fraction $\zeta_{\mathrm{w}}(t)$ at $x_{\mathrm{R}}$.

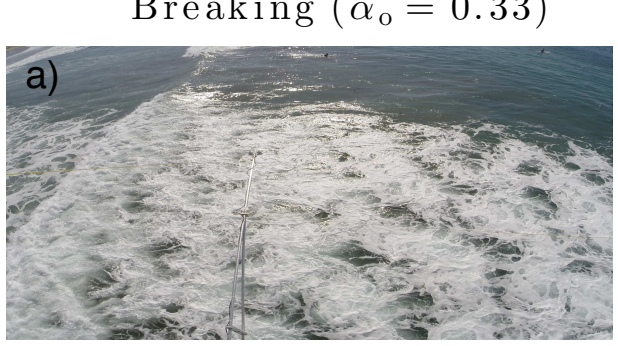

$$
\text { Non-Breaking }\left(\alpha_{\mathrm{o}}=0.05\right)
$$
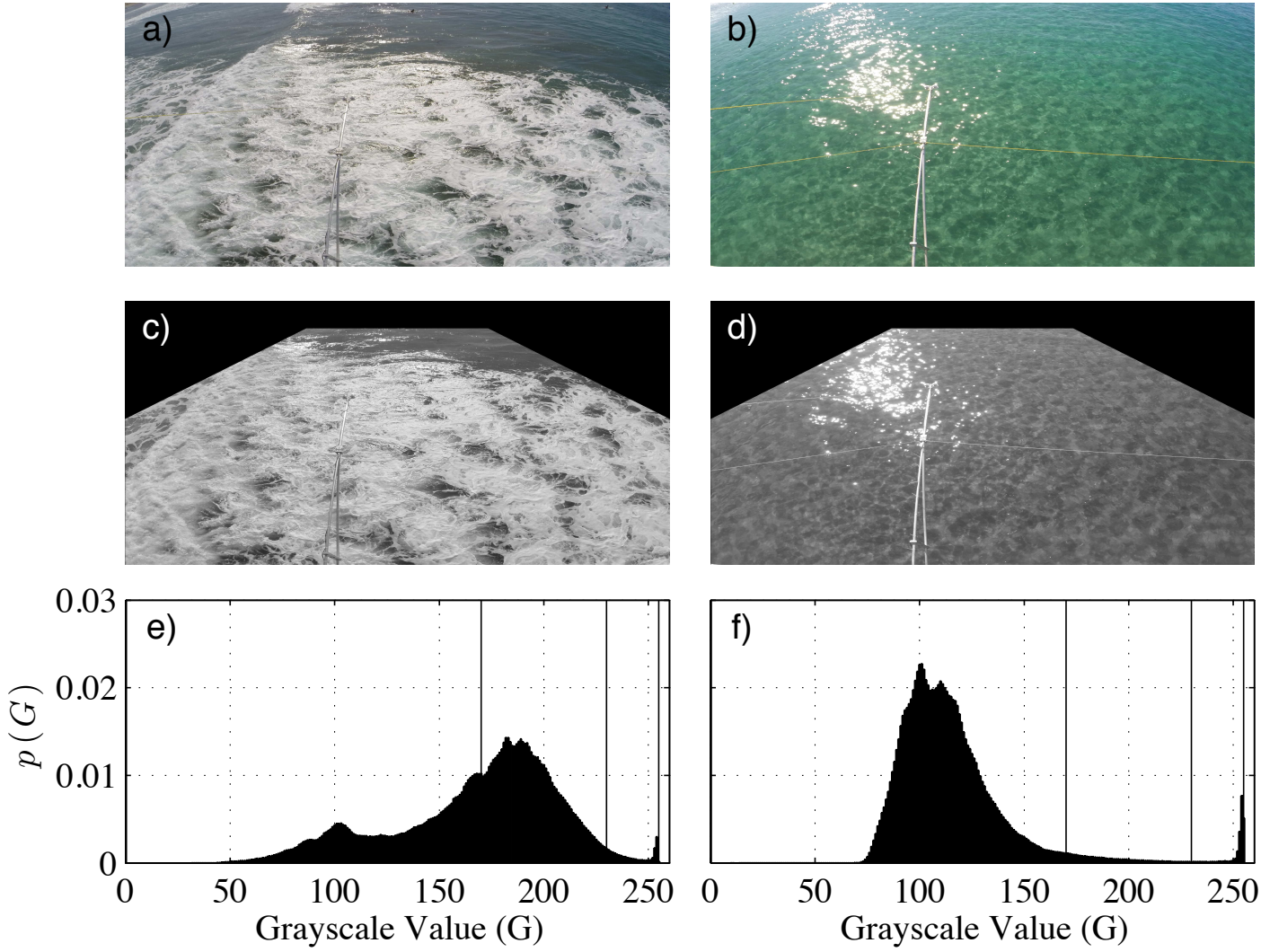

Figure 6: Images of water below the radiometer (a) during a breaking event when $\alpha_{\mathrm{o}}=0.33$ and (b) under calm non-breaking conditions when $\alpha_{\mathrm{o}}=0.05$. Cropped and grayscale converted images of (c) a breaking wave and (d) non-breaking. PDFs of the grayscale values for (e) breaking conditions and (f) non-breaking conditions are delineated (vertical black lines) to show grayscale pixel values classed as "open water" $(G<170)$, "foam" $(170<G<230)$ and "sun glint" $(G>230)$. The fraction of pixels identified as "foam" $\left(\zeta_{\mathrm{w}}\right)$ is 0.55 under breaking conditions (left), but only 0.03 for non-breaking conditions (right). 
Similar to open ocean whitecapping albedo formulations (4), the image-derived albedo $\alpha_{\mathrm{I}}$ is

$$
\alpha_{\mathrm{I}}=\zeta_{\mathrm{w}} \alpha_{\mathrm{f}}+\left(1-\zeta_{\mathrm{w}}\right) \alpha_{\theta},
$$

where $\alpha_{\theta}$ is the $\theta_{\mathrm{s}}$ dependent parameterization for foam-free water, $\zeta_{\mathrm{w}}$ is derived from the images, and the foam albedo $\alpha_{\mathrm{f}}$ is considered a free parameter. The $1-\mathrm{Hz} \alpha_{\mathrm{o}}$ varied over $0.02-0.45$, spanning a broad range of solar zenith angle $\left(13.7^{\circ}<\theta_{\mathrm{s}}<56^{\circ}\right)$, depth $(1.3<h<2.6 \mathrm{~m})$ and wave height $\left(0.45<H_{\mathrm{s}}<1.21 \mathrm{~m}\right)$ conditions. Minimizing the rms error between $\alpha_{\mathrm{I}}$ and $\alpha_{\mathrm{o}}$ results in a best fit $\alpha_{\mathrm{f}}=0.465$ and a surfzone albedo parameterization with high skill $\left(r^{2}=0.90\right.$ with binned-mean $r^{2}=0.97$, Figure 7).

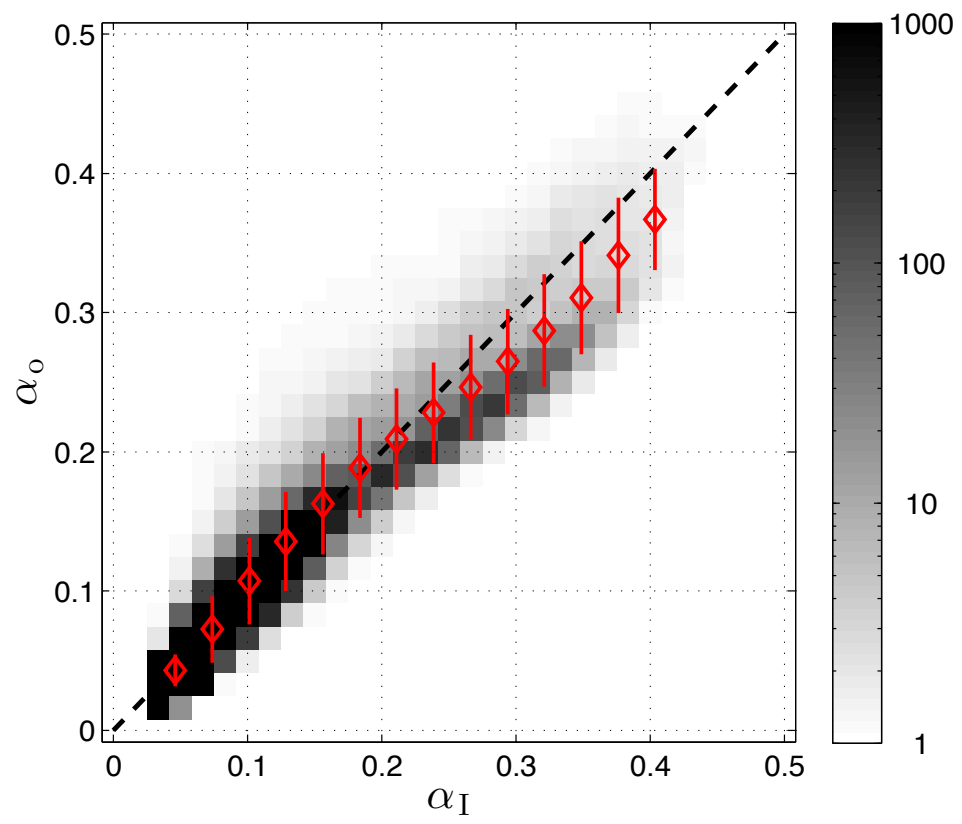

Figure 7: Gridded logarithmic density (gray scale) of image-derived albedo $\alpha_{\mathrm{I}}$ versus observed albedo $\alpha_{\mathrm{o}}$ sampled at $1 \mathrm{~Hz}$ for nine days $(N=137,547)$. The observations were made when $\theta_{\mathrm{s}}$ varied between $13.7^{\circ}$ and $56^{\circ}$, depth $h$ varied between $1.3 \mathrm{~m}$ and $2.6 \mathrm{~m}$, and pier-end $H_{\mathrm{s}}$ varied between $0.45 \mathrm{~m}$ and $1.21 \mathrm{~m}$. The best fit $\alpha_{\mathrm{f}}=0.465$ has fit skill $\mathrm{r}^{2}=0.90$ with binned mean (red diamonds) fit skill $\mathrm{r}^{2}=0.97$. Binned-mean standard deviations are represented by red lines. Bins contained at least 100 observations.

The high skill of the parameterized $\alpha_{\mathrm{I}}$ is highlighted with a ten-minute example including sev- 
eral breaking wave events from larger wave-groups at 1-2 minute intervals (Figure 8). Breaking waves caused observed albedo $\alpha_{\mathrm{o}}$ (black line, Figure 8) to increase sharply (in a few seconds), well above $\alpha_{\theta}$ (black dotted). Individual $\alpha_{\mathrm{o}}$ peaks during a large wave-group event (around $200 \mathrm{~s}$ ) were spaced near $T_{\mathrm{p}}=9 \mathrm{~s}$. The highest $\alpha_{\mathrm{o}}$ values, near 0.35 , occurred after two or more successive breaking waves almost completely covered the radiometer's field of view. Smaller $\alpha_{\mathrm{o}}$ peaks occurred when breaking events partially filled the field of view or did not break as vigorously. After the initial step-like increase lasting a few seconds, the albedo decayed toward $\alpha_{\theta}$ with time scales $\approx 20 \mathrm{~s}$ as the bubbly foam outgassed (e.g., Ma et al., 2011). The asymmetry of the observed albedo $\alpha_{\mathrm{o}}$ rapid increases and slower outgassing decay are well represented by $\alpha_{\mathrm{I}}$ (red curve, Figure 8), and $\alpha_{\mathrm{I}}$ tracks $\alpha_{\mathrm{o}}$ at both wave group and individual-wave timescales. At $\alpha_{\mathrm{o}}$ peaks (particularly $>0.2$ ), after a rapid increase, parameterized $\alpha_{\mathrm{I}}$ tends to have a high bias (Figure 8). This elevated $\alpha_{\mathrm{I}}$ bias for $\alpha_{\mathrm{o}}>0.2$ is also seen in the scatterplot (Figure 7) and is discussed further in section 4. Overall this image-based parameterization predicts the foam-induced elevated $\alpha_{\mathrm{o}}$ unexplained by $\alpha_{\theta}$ (Figure 4), and the good $\alpha_{\mathrm{I}}$ and $\alpha_{\mathrm{o}}$ time-series agreement (Figure 8) is also seen at other times and over a wide variety of surfzone conditions.

\subsection{Wave Model Based Albedo Parameterization}

Although the image-based parameterization has very high skill, a camera is required, which often is not available. However, given knowledge of one dimensional $h(x)$, wave transformation models have high skill in predicting the cross-shore evolution of wave height (e.g., Ruessink et al., 2001, 2003). This motivates a second albedo parameterization that utilizes a wave model to relate roller dissipation to foam fraction and albedo through (4).

Assuming normally-incident narrow-banded waves on alongshore uniform beaches, one-dimensional wave and roller transformation models (e.g., Thornton and Guza, 1983; Battjes and Stive, 1985; 


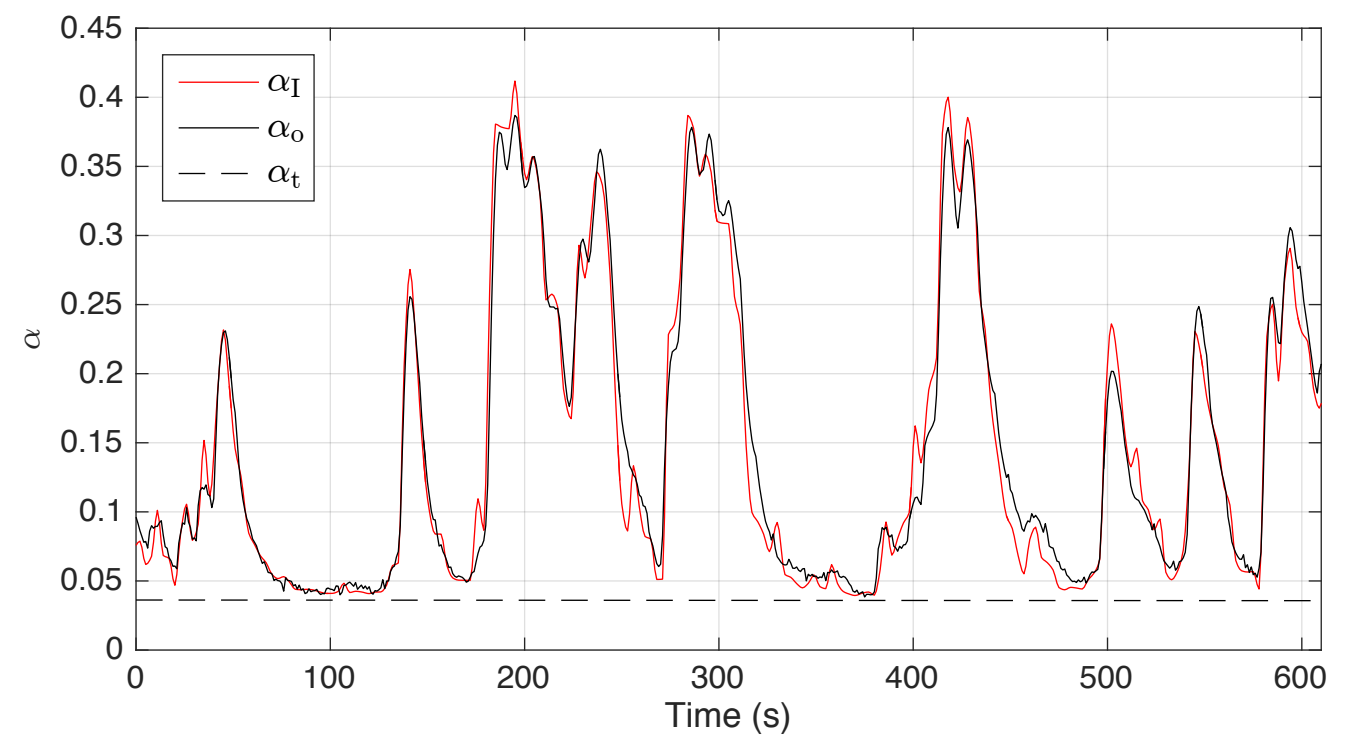

Figure 8: Ten-minute time series of image-derived albedo $\alpha_{\mathrm{I}}$ (red), observed albedo $\alpha_{\mathrm{o}}$ (black) and parameterized open ocean albedo $\alpha_{\theta}$ (dashed) beginning near noon on September 11, 2015. Water depth $h\left(x_{\mathrm{R}}\right)=1.5 \mathrm{~m}$ with moderate waves $\left(H_{\mathrm{s}}=0.6 \mathrm{~m}\right.$ and $T_{\mathrm{p}}=9 \mathrm{~s}$ at the pier-end $)$ and light winds $\left(\left|u_{\mathrm{w}}\right|=3.7 \mathrm{~m} \mathrm{~s}^{-1}\right)$ with $\theta_{\mathrm{s}}=31^{\circ}$

Ruessink et al., 2001) relate wave energy flux gradient to wave-energy dissipation,

$$
\frac{d}{d x}\left(E C_{g}\right)=-\left\langle\epsilon_{b}\right\rangle
$$

where $E$ is the wave energy density, $C_{g}$ is the group velocity given by linear theory, and $\left\langle\epsilon_{b}\right\rangle$ is the bulk breaking wave dissipation. The wave energy density is $E=1 / 16 \rho g H_{\mathrm{s}}^{2}$ where $\rho$ is water density, $g$ is gravity and $H_{\mathrm{s}}$ is the local significant wave height. The breaking wave dissipation $\left\langle\epsilon_{b}\right\rangle$ is given by Church and Thornton (1993) with standard breaking parameters $(B=0.9$ and $\gamma=0.57)$. The roller energy equation is (e.g., Ruessink et al., 2001)

$$
\frac{d}{d x}\left(2 E_{\mathrm{r}} c\right)=-\left\langle\epsilon_{r}\right\rangle+\left\langle\epsilon_{b}\right\rangle
$$

where $E_{\mathrm{r}}$ is the roller energy density and $c$ is the linear theory phase speed. Roller dissipation is 
defined as (Deigaard, 1993)

$$
\left\langle\epsilon_{r}\right\rangle=\frac{2 g E_{\mathrm{r}} \sin \beta}{c}
$$

with slope $\beta=0.1$ (e.g., Walstra et al., 1996). The coupled equations ( 8 and 9 ) are solved with the specified $h(x)$ and offshore (pier-end) boundary conditions of observed $H_{\mathrm{s}}$ and $T_{\mathrm{p}}$, with $E_{\mathrm{r}}=0$.

Example output from the wave and roller model characterizes the cross-shore evolution of $H_{\mathrm{s}}$ (Figure 9a) due to the bathymetric profile (Figure 9e). As waves shoal onshore, wave height increases to $H_{\mathrm{s}}=1.5 \mathrm{~m}$ at $x=-170 \mathrm{~m}$ where breaking occurs, roller dissipation becomes non-zero (Figure 9b) and wave height decreases. The terraced, non-monotonic bathymetry create undulating regions of elevated $\left\langle\epsilon_{r}\right\rangle$ (e.g., near $x=140 \mathrm{~m}, x=90 \mathrm{~m}$, Figure $\left.9 \mathrm{~b}\right)$ and weaker $\left\langle\epsilon_{r}\right\rangle$ (e.g., near $x=125 \mathrm{~m}$ and $x=65 \mathrm{~m}$ ).

To develop a wave-model based albedo parameterization $\alpha_{\mathrm{w}}$, the average foam fraction $\left\langle\zeta_{\mathrm{w}}\right\rangle$ is hypothesized to depend linearly on non-dimensional $(\widehat{)})$ wave roller dissipation $\left\langle\widehat{\epsilon_{r}}\right\rangle$ as

$$
\left\langle\zeta_{\mathrm{w}}\right\rangle=m\left\langle\widehat{\epsilon_{r}}\right\rangle
$$

where $\left\langle\widehat{\epsilon_{r}}\right\rangle$ is non-dimensionalized by wave-dissipation scaling (e.g., Battjes, 1975; Feddersen and Trowbridge, 2005; Feddersen, 2012a,b) as

$$
\left\langle\widehat{\epsilon_{r}}\right\rangle=\frac{\left\langle\epsilon_{r}\right\rangle}{\rho(g h)^{3 / 2}}
$$

and $m$ is a fit parameter found by minimizing rms error between $\alpha_{\mathrm{o}}$ and $\alpha_{\mathrm{w}}$. The hourly averaged wave-model based albedo is found from (4) using $\left\langle\zeta_{\mathrm{w}}\right\rangle$ and $\alpha_{\mathrm{f}}=0.465$ as in section 3.2. The radiometer observed $\alpha_{\mathrm{o}}$ is a cosine angle weighted area-average with $\approx 14 \mathrm{~m}$ radius. To compare the observed albedo with the parameterized albedo, $\left\langle\zeta_{\mathrm{w}}\right\rangle$ is also area-averaged with an identical cosine weighted response centered at $x_{\mathrm{R}}$. The resulting foam fraction $\overline{\left\langle\zeta_{\mathrm{w}}\right\rangle}$ is both time and area averaged (where denotes an area average) and the resulting time and area averaged wave-model 

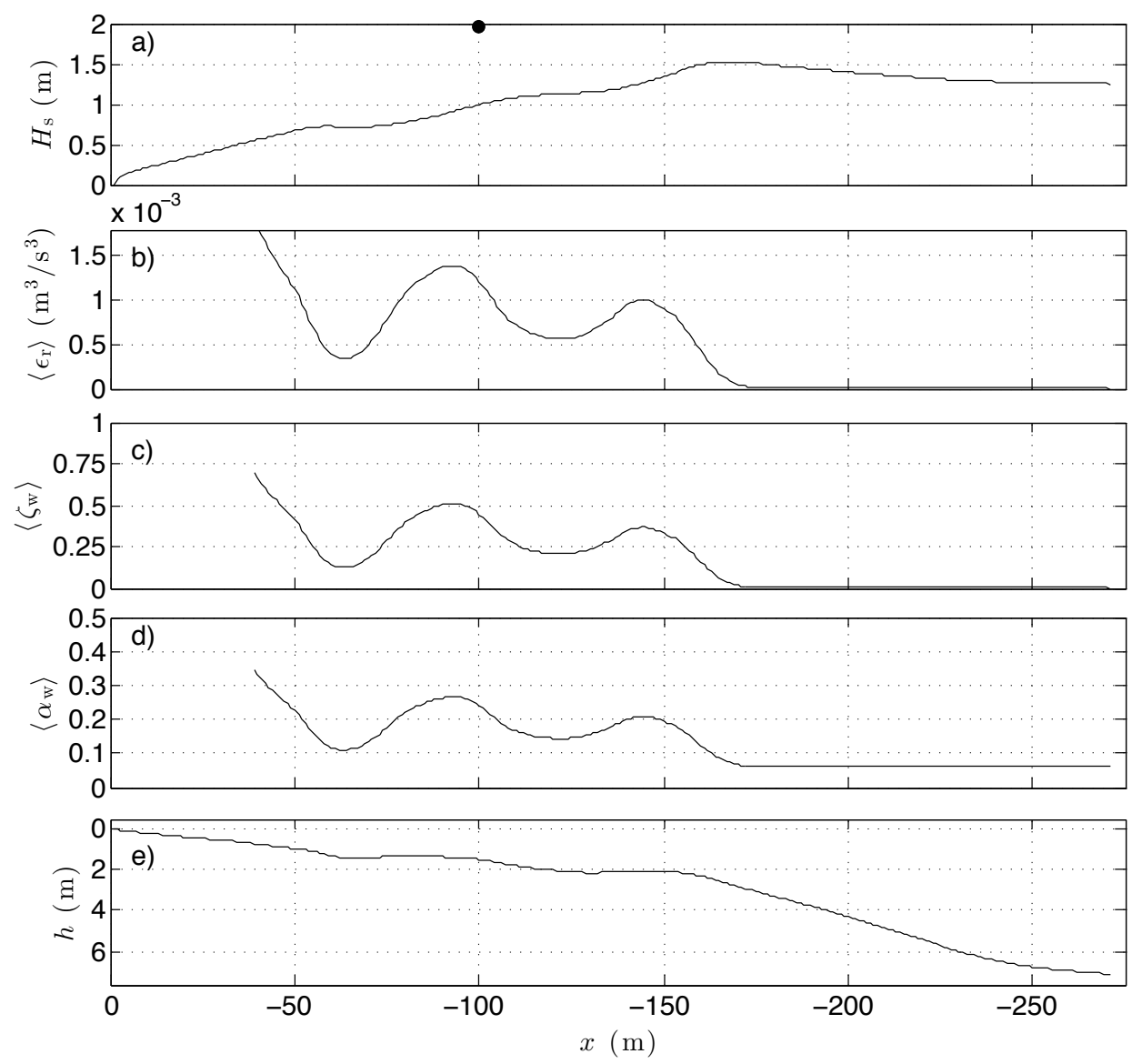

Figure 9: (a) Modeled significant wave height $H_{\mathrm{s}}$, (b) modeled wave-roller dissipation $\left\langle\epsilon_{r}\right\rangle$, (c) inferred mean foam fraction $\left\langle\zeta_{w}\right\rangle$, (d) wave-model parameterized albedo $\left\langle\alpha_{w}\right\rangle$, and (e) bathymetry profile $h(x)$ versus cross-shore coordinate $x$ for noon on February 8, 2015. The black dot indicates the radiometer cross-shore location $\left(x_{\mathrm{R}}\right)$, which measured $\left\langle\alpha_{\mathrm{o}}\right\rangle=0.27$ under clear skies $(T>0.6)$ while $\theta_{\mathrm{s}} \approx 48^{\circ}$ at this time. The wave model was initialized with one-hour averaged $H_{\mathrm{s}}=1.3 \mathrm{~m}$ and $T_{\mathrm{p}}=13.4 \mathrm{~s}$ measured at the pier-end (assuming incident waves). Modeled quantities are not shown for $h<0.5 \mathrm{~m}$. 


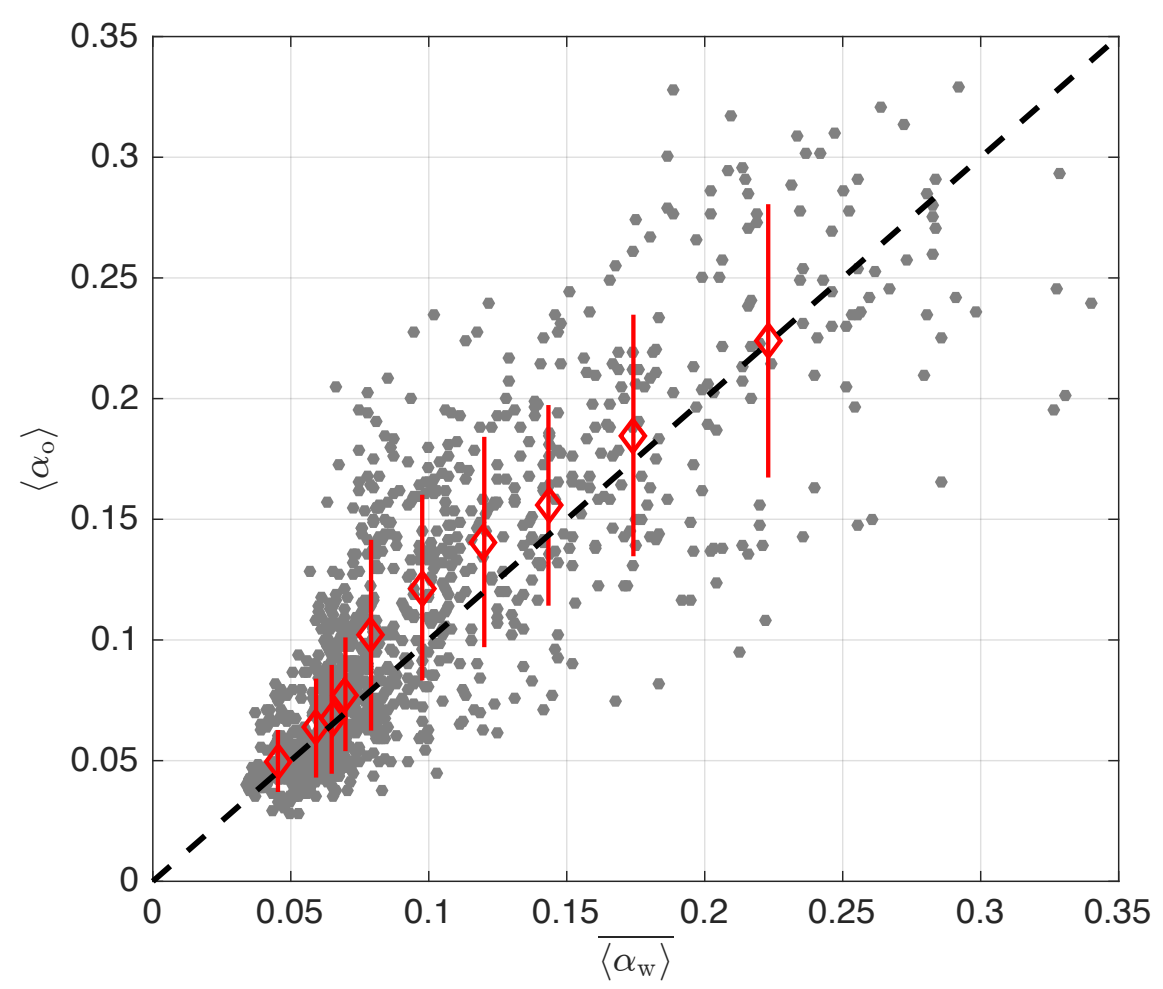

Figure 10: Hourly-averaged observed albedo $\left\langle\alpha_{\mathrm{o}}\right\rangle$ versus the wave-model albedo parameterization $\overline{\left\langle\alpha_{\mathrm{w}}\right\rangle}(N=1169)$. The $1: 1$ line (dotted) is shown with binned means (red diamonds) and \pm standard deviation (red lines). The best fit slope $m=398$ and skill $r^{2}=0.68$ (binned-mean $\left.r^{2}=0.94\right)$.

based albedo $\overline{\left\langle\alpha_{\mathrm{w}}\right\rangle}$ is found from (4).

When the radiometer sampled the surfzone (at $x_{\mathrm{R}}, H_{\mathrm{s}} / h \geq 0.57$ ), the mean observed surfzone albedo $\alpha_{\mathrm{o}}$ was 0.15 , over twice the daily average open ocean albedo parameterization of 0.06 . The observed hourly averaged albedo $\left\langle\alpha_{\mathrm{o}}\right\rangle$ varied between 0.04 and 0.33 , greater than the open ocean albedo parameterization more than $80 \%$ of the time. The parameterized $\overline{\left\langle\alpha_{\mathrm{w}}\right\rangle}$ was a good predictor of $\left\langle\alpha_{\mathrm{o}}\right\rangle$ with significant skill $\left(r^{2}=0.68\right)$ when best fit parameter $m=398$ (dots in Figure 10). The parameterized binned mean $\overline{\left\langle\alpha_{\mathrm{w}}\right\rangle}$ (red diamonds in Figure 10) has high skill $\left(r^{2}=0.94\right)$ over these widely ranging and elevated albedo conditions. Factors contributing to variance in the binned quantities is discussed in section 4 .

Although $\overline{\left\langle\alpha_{\mathrm{w}}\right\rangle}$ is generated from hourly-averaged wave statistics, $\overline{\left\langle\alpha_{\mathrm{w}}\right\rangle}$ is able to track albedo 
changes on time scales related to $\theta_{\mathrm{s}}, h$ and $H_{\mathrm{s}}$ (Figure 11). For example, over six days, the combined effects of $\theta_{\mathrm{S}}$ and wave energy at $x_{\mathrm{R}}$ cause the daily average of both $\left\langle\alpha_{\mathrm{o}}\right\rangle$ and $\overline{\left\langle\alpha_{\mathrm{w}}\right\rangle}$ to vary between 0.06 and 0.18 . Albedo also varied by 0.16 in only 4 hours on day 2 associated with changes in $H_{\mathrm{s}} / h$, yet there is still good agreement between $\overline{\left\langle\alpha_{\mathrm{w}}\right\rangle}$ and $\left\langle\alpha_{\mathrm{o}}\right\rangle$. Albedo estimation at specific cross-shore locations is also possible. The parameterized cross-shore foam fraction $\left\langle\zeta_{\mathrm{w}}\right\rangle$ varies from zero offshore to local maxima of $\left\langle\zeta_{\mathrm{w}}\right\rangle=0.3$ and $\left\langle\zeta_{\mathrm{w}}\right\rangle=0.5$ at $x=-140 \mathrm{~m}$ and $x=-90 \mathrm{~m}$, respectively (Figure 9c), consistent with the range of image inferred $\zeta_{\mathrm{w}}$. The resulting $\left\langle\alpha_{\mathrm{w}}\right\rangle(x)$ (Figure 9d) is frequently above the $\theta_{\mathrm{s}}$ dependent parameterization at this time $\left(\alpha_{\theta}=0.06\right)$ which is only valid in locations where there is no breaking. Surfzone albedo can also be parameterized with non-dimensionalized roller-energy instead of roller dissipation, with similar skill.

\section{Discussion}

Elevated surfzone albedo can impact heat budgets (Sinnett and Feddersen, 2014) and pathogen mortality (e.g., Sinton et al., 2002). Water-entering short-wave solar radiation $Q_{\mathrm{sw}}$ is the largest surfzone heat budget term (Sinnett and Feddersen, 2014). An average surfzone albedo increase from $\alpha=0.06$ to (as observed) $\alpha=0.15$ would reduce $Q_{\text {sw }}$ so that cross-shore advection or wave heating are relatively more important. For example, the Sinnett and Feddersen (2014) heat budget found a residual surfzone heat export of $5.2 \times 10^{3} \mathrm{Wm}^{-1}$. Revising the heat budget using $\alpha=0.15$, reduces the residual heat export by $30 \%$. Dye tracer can linger in the surfzone for $>12 \mathrm{~h}$ (Hally-Rosendahl et al., 2014), indicating the time-scales pathogens can remain in bathing waters. Increasing albedo from 0.06 to 0.15 roughly doubles fecal coliform bacterial survival rates (Sinton et al., 2002), increasing potential human health risk if not appropriately accounted for.

The observed albedo $\alpha_{\mathrm{o}}$ is a space and time-average over the radiometer's 14-m radius cosine response and 2.9 s time constant. With propagating breaking waves which continuously outgas 

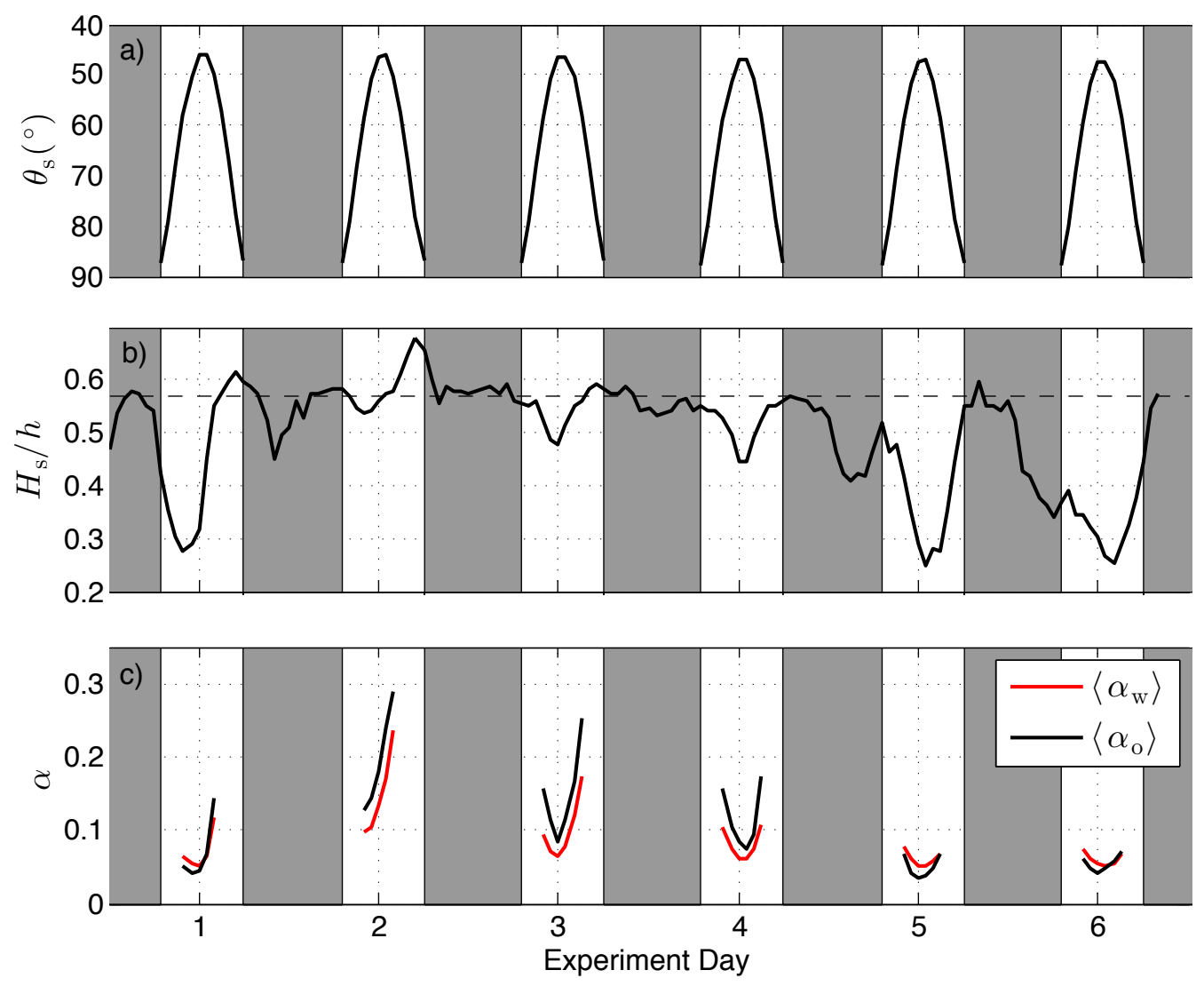

Figure 11: Six day time series (October 25-30, 2014) of (a) solar zenith angle $\theta_{\mathrm{s}}$, (b) depth normalized significant wave height $H_{\mathrm{s}} / h$ at $x_{\mathrm{R}}$ with expected threshold of significant wave breaking (dotted) (c) observed albedo $\left\langle\alpha_{\mathrm{o}}\right\rangle$ (black) and wave parameterized albedo $\left\langle\alpha_{\mathrm{w}}\right\rangle$ (red). Nighttime $\left(\theta_{\mathrm{s}}>90\right)$ is shaded.

bubbles, the radiometer will never instantaneously sample pure foam over its entire field of view. This may explain why the best-fit foam albedo $\alpha_{\mathrm{f}}=0.465$ is less than the laboratory observed maximum value of 0.55 (Whitlock et al., 1982). Although the image-based $\alpha_{\text {I }}$ predicts $\alpha_{\mathrm{o}}$ with high skill (Figure 7), for $\alpha_{\mathrm{o}}>0.2, \alpha_{\mathrm{I}}$ is biased high particularly when a breaking wave front passes and $d \alpha / d t$ is large (Figure 8 ). The $2.9 \mathrm{~s}$ radiometer response time, relative to the nearinstantaneous camera response time, may explain this bias at times of step function-like changes in albedo.

The specific grayscale PDF cutoff limits for open water, foam, and sun glint, derived from $\bar{p}^{\prime \prime}(G)$ extrema, are the result of the lighting and fixed camera settings at this location. To apply 
this parameterization with another camera or at another location, one must first establish the relevant $\bar{p}^{\prime \prime}(G)$ based cutoff limits. This method can also be applied to time-averaged images. Good agreement between $\alpha_{\mathrm{I}}$ and $\alpha_{\mathrm{o}}$ was found with a constant foam albedo $\alpha_{\mathrm{f}}$ applied to grayscale values within the foam cutoff limits. The fit may be improved if $\alpha_{\mathrm{f}}$ is a function of $G$. Furthermore, images were not georectified. The images were cropped to limit the field of view to a relatively small area beneath the radiometer, and the $45^{\circ}$ camera angle caused the imaged pixel area to have a similar spatial response as the radiometer. For example, the pixels near the top of the image cover roughly $35 \%$ more area than the pixels near the bottom, and the radiometer cosine response reduces the signal by roughly $40 \%$ near the top of the image. As the camera and radiometer were sampling with similar spatial weights, image rectification was not needed. However, image rectification may be required if this parameterization technique is applied to images covering a wider area (e.g., ARGUS), or to images taken at shallower angles.

When breaking occurs, $\left\langle\alpha_{\mathrm{o}}\right\rangle$ is elevated above $\alpha_{\theta}$ (Figures 3,4), and the wave-model based parameterization has good skill $\left(r^{2}=0.68\right)$ in predicting $\alpha_{\mathrm{o}}$ (Figure 10), although significant unexplained variance remains. Waves were assumed to be normally-incident (as expected for long-period waves in $h<6 \mathrm{~m}$ ), and standard wave and roller model coefficients were used. The bathymetry near piers is often scoured (Elgar et al., 2001), which may result in pier-based bathymetry measurement errors. Depth $h$ errors and wave model errors would induce roller energy dissipation $\left\langle\epsilon_{\mathrm{r}}\right\rangle$ errors, and eventually $\left\langle\alpha_{\mathrm{w}}\right\rangle$ errors, potentially contributing to the unexplained variance in Figure 10.

\section{Summary}

Breaking-wave induced foam elevates albedo $\alpha$ relative to foam-free ocean. Open-ocean albedo parameterizations account for foam through a wind speed dependent whitecapping foam fraction $\zeta_{\mathrm{w}}$. However, surfzone depth-limited wave breaking does not depend on wind, and wind-based 
foam fraction parameterizations are inaccurate in the surfzone. Measuring albedo in the energetic surfzone environment is difficult, and observations of surfzone albedo are very rare. The variability of surfzone albedo is not known, and parameterizations have not been available. Oceanentering shortwave solar radiation $Q_{\mathrm{sw}}$ depends on albedo and affects both temperature variability and pathogen mortality. This motivates new observations of surfzone albedo and the development of two surfzone albedo parameterizations based on camera images and a wave model.

A year-long experiment at the Scripps Institution of Oceanography pier observed upwelling $Q_{\mathrm{u}}$ and downwelling $Q_{\mathrm{d}}$ shortwave radiation spanning the surfzone and inner-shelf over a range of wave and depth conditions. A two-way radiometer was mounted $6.5 \mathrm{~m}$ above the mean ocean surface and $6.35 \mathrm{~m}$ away from the pier, limiting pier shadow effects. Additional wave, wind, tidal and bathymetric observations were collected. On nine days, a downward-looking GoPro camera fixed above the radiometer location continuously captured water surface images. For solar zenith angle $\theta_{\mathrm{s}}<60^{\circ}$, one-minute averaged observed albedo (as large as $\alpha_{\mathrm{o}}=0.45$ ) far exceeded the open ocean solar zenith angle parameterized albedo of 0.06 . The elevated observed albedo was related to breaking wave conditions under the radiometer and observed albedo was not related to the wind speed.

A surfzone albedo parameterization is developed using images to estimate foam fraction $\zeta_{\mathrm{w}}$, identified by the distribution of grayscale pixels values. This image-based parameterization has high skill $\left(r^{2}=0.90\right)$, with a best-fit parameter for foam albedo of $\alpha_{\mathrm{f}}=0.465$, slightly less than laboratory maximum of 0.55 likely due to radiometer finite time and spatial response. This parameterization captures albedo variability on the time-scales of individual waves $(9 \mathrm{~s})$ and wave groups (minutes).

A wave-model based parameterization relates non-dimensionalized wave roller energy dissipation to the hourly-averaged foam fraction $\left\langle\zeta_{w}\right\rangle$ and, thus, to albedo. The wave model is initiated with bathymetry and incident wave conditions. This parameterization predicts hourly averaged observations from the radiometer, has good skill $\left(r^{2}=0.68\right)$, and can resolve cross-shore albedo 
variations. Bathymetry or wave model errors may contribute to unexplained variance. These new parameterizations are applicable where imagery (e.g., ARGUS) or nearshore wave models are available, and can be used to constrain local heat budgets and pathogen mortality estimation.

\section{Acknowledgments}

This work was supported in part by ONR and NSF. Gregory Sinnett was supported by a NSF GK12 fellowship and the SIO graduate department. Radiometer boom arm was developed and deployed by B. Woodward, B. Boyd, K. Smith, and R. Grenzeback. Deployment and recovery above difficult surfzone conditions was aided by C. McDonald, R. Walsh, S. Mumma, G. Boyd, L. Parry and the San Diego lifeguards. G. Castelao helped maintain the radiometer during deployment. Wave data was provided by the Coastal Data Information Program (CDIP) with special assistance from W. O'Reilly and C. Olfe. Wind and tidal data was gathered from NOAA station 9410230. Two anonymous reviewers significantly improved this manuscript. We would like to sincerely thank these people and organizations. 


\section{References}

Almar, R., B. Castelle, B. Ruessink, N. Sénéchal, P. Bonneton, and V. Marieu (2010), Two- and three-dimensional double-sandbar system behaviour under intense wave forcing and a meso-macro tidal range, Continental Shelf Research, 30(7), 781 - 792, doi: http://dx.doi.org/10.1016/j.csr.2010.02.001.

Battjes, J. (1975), Modeling of turbulence in the surfzone, in Proc. Symposium Modeling Techniques, pp. 1050-1061, ASCE.

Battjes, J. A., and M. J. F. Stive (1985), Calibration and verification of a dissipation model for random breaking waves, Journal of Geophysical Research: Oceans, 90(C5), 9159-9167, doi: 10.1029/JC090iC05p09159.

Briegleb, B., P. Minnis, V. Ramanathan, and E. Harrison (1986), Comparison of regional clear-sky albedos inferred from satelliete observations and model computations, Journal of Climate and Applied Meteorology, 25, 214-226.

Broitman, B., C. Blanchette, and S. Gaines (2005), Recruitment of intertidal invertebrates and oceanographic variability at Santa Cruz Island, California, Limnology and Oceanography, 50(5), 1473-1479.

Carini, R. J., C. C. Chickadel, A. T. Jessup, and J. Thomson (2015), Estimating wave energy dissipation in the surf zone using thermal infrared imagery, Journal of Geophysical Research: Oceans, 120(6), 3937-3957, doi:10.1002/2014JC010561.

Chickadel, C. C., R. A. Holman, and M. H. Freilich (2003), An optical technique for the measurement of longshore currents, Journal of Geophysical Research: Oceans, 108(C11), n/a-n/a, doi:10.1029/2003JC001774, 3364.

Church, J., and E. Thornton (1993), Effects of breaking wave-induced turbulence within a longshore-current model, Coastal Eng., 20(1-2), 1-28.

Coakley, J. A., and R. Davies (1986), The effect of cloud sides on reflected solar radiation as deduced from satellite observations, Journal of the Atmospheric Sciences, 43(10), 1025-1035, doi:10.1175/1520-0469(1986)043;1025:TEOCSO ¿2.0.CO;2.

Davies, R. (1978), The effect of finite geometry on the three-dimensional transfer of solar irradiance in clouds, Journal of the Atmospheric Sciences, 35(9), 1712-1725, doi:10.1175/15200469(1978)035;1712:TEOFGO i2.0.CO;2.

Deigaard, R. (1993), A note on the three dimensional shear stress distribution in a surfzone, Coastal Engineering, 20, 157-171.

Elgar, S., R. T. Guza, W. C. O’Reilly, B. Raubenheimer, and T. H. C. Herbers (2001), Wave energy and direction observed near a pier, J. Waterw. Port Coastal Ocean Eng., 127, 2-6. 
Feddersen, F. (2012a), Scaling surfzone dissipation, Geophys. Res. Lett., 39(L18613).

Feddersen, F. (2012b), Observations of the surfzone turbulent dissipation rate, J. Phys. Ocean., 42, 386-399, doi:10.1175/JPO-D-11-082.1.

Feddersen, F., and J. H. Trowbridge (2005), The effect of wave breaking on surf-zone turbulence and alongshore currents: a modelling study, J. Phys. Ocean., 35, 2187-2204.

Fischer, S., and S. Thatje (2008), Temperature-induced oviposition in the brachyuran crab Cancer setosus along a latitudinal cline: Aquaria experiments and analysis of field-data, J. Experimental Marine Biology and Ecology, 357(2), 157-164, doi:10.1016/j.jembe.2008.01.007.

Frouin, R., M. Schwindling, and P.-Y. Deschamps (1996), Spectral reflectance of sea foam in the visible and near-infrared: In situ measurements and remote sensing implications, J. Geophys. Res., 101(C6), 14,361-14,371, doi:10.1029/96JC00629.

Frouin, R., S. F. Iacobellis, and P.-Y. Deschamps (2001), Influence of oceanic whitecaps on the global radiation budget, Geophysical Research Letters, 28(8), 1523-1526, doi: 10.1029/2000GL012657.

Goodwin, K. D., M. McNay, Y. Cao, D. Ebentier, M. Madison, and J. F. Griffith (2012), A multibeach study of Staphylococcus aureus, MRSA, and enterococci in seawater and beach sand, Water Research, 46(13), 4195-4207, doi:10.1016/j.watres.2012.04.001.

Halliday, E. E. A. (2012), Sands and environmental conditions impact the abundance and persistence of the fecal indicator bacteria enterococcus at recreational beaches, Ph.D. thesis, Massachusetts Institute of Technology.

Hally-Rosendahl, K., F. Feddersen, and R. T. Guza (2014), Cross-shore tracer exchange between the surfzone and the inner-shelf, J. Geophys. Res., submitted.

Hansen, J., G. Russell, D. Rind, P. Stone, A. Lacis, S. Lebedeff, R. Ruedy, and L. Travis (1983), Efficient three-dimensional global models for climate studies: Models i and ii, Mon. Weather Rev, 111, 609-662.

Holland, K., R. Holman, T. Lippmann, J. Stanley, and N. Plant (1997), Practical use of video imagery in nearshore oceanographic field studies, Oceanic Engineering, IEEE Journal of, 22(1), 81-92, doi:10.1109/48.557542.

Jin, Z., Y. Qiao, Y. Wang, Y. Fang, and W. Yi (2011), A new parameterization of spectral and broadband ocean surface albedo, Optics Express, 19(27).

Jin, Z., T. Charlock, W. Smith, and K. Rutledge (2004), A parameterization of ocean surface albedo, Geophysical Research Letters, 31(22), doi:10.1029/2004GL021180.

Koepke, P. (1984), Effective reflectance of oceanic whitecaps, Applied Optics, 23(11). 
Lippmann, T., and R. Holman (1990), The spatial and temporal variability of sand-bar morphology, J. Geophys. Res., 95(C7), 11,575-11,590, doi:10.1029/JC095iC07p11575.

Ludka, B. C., R. T. Guza, W. C. O'Reilly, and M. L. Yates (2015), Field evidence of beach profile evolution toward equilibrium, J. Geophys. Res., Oceans, 120.

Ma, G., F. Shi, and J. T. Kirby (2011), A polydisperse two-fluid model for surf zone bubble simulation, Journal of Geophysical Research: Oceans, 116(C5), n/a-n/a, doi:10.1029/2010JC006667, c05010.

Monahan, E., G. Niocaill, and P. Koepke (1986), Oceanographic Sciences Library, vol. 2, pp. 251-260, Springer Netherlands, doi:10.1007/978-94-009-4668-2_23.

Monahan, E. C. (1971), Oceanic whitecaps, Journal of Physical Oceanography, 1(2), 139-144, doi:10.1175/1520-0485(1971)001;0139:OW 2 2.0.CO;2.

Monahan, E. C., and I. Muircheartaigh (1980), Optimal power-law description of oceanic whitecap coverage dependence on wind speed, Journal of Physical Oceanography, 10(12), 2094-2099, doi:10.1175/1520-0485(1980)010;2094:OPLDOO ¿2.0.CO;2.

Moore, K. D., K. J. Voss, and H. R. Gordon (2000), Spectral reflectance of whitecaps: Their contribution to water-leaving radiance, Journal of Geophysical Research: Oceans, 105(C3), 6493-6499, doi:10.1029/1999JC900334.

O'Reilly, W., and R. Guza (1991), Comparison of spectral refraction and refraction-diffraction wave models, Journal of Waterway Port Coastal and Ocean Engineering-ASCE, 117(3), 199215.

O'Reilly, W., and R. Guza (1998), Assimilating coastal wave observations in regional swell predictions. Part I: Inverse methods, J. Phys. Ocean., 28(4), 679-691.

Payne, R. E. (1972), Albedo of the sea surface, J. Atmos. Sci., 29, 959-970.

Phillips, N. (2005), Growth of filter-feeding benthic invertebrates from a region with variable upwelling intensity, Marine Ecology Progress Series, 295, 79-89, doi:10.3354/meps295079.

Reda, I., and A. Andreas (2008), Solar position algorithm for solar radiation applications (revised), Tech. rep., Golden, CO.

Rippy, M. A., P. J. S. Franks, F. Feddersen, R. T. Guza, and D. F. Moore (2013a), Factors controlling variability in nearshore fecal pollution: Fecal indicator bacteria as passive particles, Mar. Poll. Bull., 66, 151-157, doi:10.1016/j.marpolbul.2012.09.030.

Rippy, M. A., P. J. S. Franks, F. Feddersen, R. T. Guza, and D. F. Moore (2013b), Factors controlling variability in nearshore fecal pollution: The effects of mortality, Marine Pollution Bulletin, 66(1-2), 191-198, doi:10.1016/j.marpolbul.2012.09.003. 
Ross, V., and D. Dion (2007), Sea surface slope statistics derived from sun glint radiance measurements and their apparent dependence on sensor elevation, Journal of Geophysical Research: Oceans, 112(C9), n/a-n/a, doi:10.1029/2007JC004137, c09015.

Ruessink, B., D. Walstra, and H. Southgate (2003), Calibration and verification of a parametric wave model on barred beaches, Coastal Engineering, 48(3), 139 - 149, doi: http://dx.doi.org/10.1016/S0378-3839(03)00023-1.

Ruessink, B. G., J. R. Miles, F. Feddersen, R. T. Guza, and S. Elgar (2001), Modeling the alongshore current on barred beaches, J. Geophys. Res., 106, 22,451-22,463.

Saunders, P. M. (1967), Shadowing on the ocean and the existence of the horizon, J. Geophys. Res., 72(18), 4643-4649.

Sinnett, G. H., and F. Feddersen (2014), The surf zone heat budget: The effect of wave heating, Geophysical Research Letters, 41, doi:10.1002/2014GL061398.

Sinton, L., R. Davies-Colley, and R. G. Bell (1994), Inactivation of enterococci and fecal coliforms from sewage and meatworks effluents in seawater chambers, Applied and Environmental Microbiology, 60(6), 2040-2048.

Sinton, L., C. Hall, P. Lynch, and R. Davies-Colley (2002), Sunlight inactivation of fecal indicator bacteria and bacteriophages from waste stabilization pond effluent in fresh and saline waters, Applied and Environmental Microbiology, 68(3), 1122-1131.

Stockdon, H. F., and R. A. Holman (2000), Estimation of wave phase speed and nearshore bathymetry from video imagery, Journal of Geophysical Research: Oceans, 105(C9), 22,01522,033, doi:10.1029/1999JC000124.

Taylor, J., J. Edwards, M. Glew, P. Hignett, and A. Slingo (1996), Studies withi a flexible new radiation code. ii: Comparisons with aircraft short-wave observations, Q. J. R. Meteorol. Soc., $122,839-861$.

Thornton, E. B., and R. T. Guza (1983), Transformation of wave height distribution, J. Geophys. Res., 88(C10), 5925-5938.

Walstra, D., G. P. Mocke, and F. Smit (1996), Roller contributions as inferred from inverse modelling techniques, Proceedings 25th International Coastal Engineering Conference, pp. 12051218.

Whitlock, C. H., D. S. Bartlett, and E. A. Gurganus (1982), Sea foam reflectance and influence on optimum wavelength for remote sensing of ocean aerosols, Geophysical Research Letters, 9(6), 719-722, doi:10.1029/GL009i006p00719. 